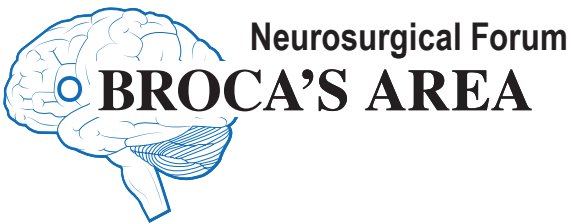

\section{Approach selection for intrinsic brainstem pathologies}

*M. Yashar S. Kalani, MD, PhD, Kaan Yagmurlu, MD, Nikolay L. Martirosyan, MD, Daniel D. Cavalcanti, MD, and Robert F. Spetzler, MD

Department of Neurosurgery, Barrow Neurological Institute, St. Joseph's Hospital and Medical Center, Phoenix, AZ

$\mathrm{W}$ ITH the exception of lesions treated at select specialty centers, lesions in the brainstem are not routinely removed. This reluctance to treat these lesions is based on the premise that the surgeon's intervention should improve upon the natural history of the pathology being treated and should not add morbidity to the patient without improving this natural history. Operating in these regions is made challenging by the need to traverse a high density of critical neural pathways; interruption of these pathways often results in temporary or, more rarely, permanent deficits in patients. Unlike intrinsic infiltrative tumors of the neuroaxis (some of which may be resected when exophytic), noninfiltrative pathologies in the brainstem can frequently be resected with acceptable morbidity. ${ }^{1,8,14,32}$ To optimize the resection of lesions while decreasing operative risk to the patient, the surgeon must select an approach that allows direct access to the lesion. Ideally, the approach uses the shortest distance, although this is not possible in every case, while minimally disturbing adjacent neural pathways. In this report, based on 40 years of experience with brainstem surgery, we describe the technique of combining safe-entry zones ${ }^{7}$ and the twopoint method ${ }^{6}$ to select the optimal approach to brainstem lesions and we highlight pitfalls of surgical techniques.

\section{Preoperative Planning}

The ultimate success of an operation in the brainstem depends largely on preoperative planning and preparation. Selection of the proper approach is certainly a key component of preparation.

\section{Monitoring for Brainstem Surgery}

We monitor somatosensory evoked potentials and motor evoked responses for all brainstem cases. We monitor the function of cranial nerves on the basis of lesion location, and several studies have documented the importance and utility of monitoring modalities. ${ }^{24,37}$ The intraoperative monitoring of the cranial nuclei is based on intraoperative electrophysiological findings and the compound muscle action potentials from related muscles. The treatment of pontine lesions located close to the floor of the fourth ventricle requires the precise identification of the facial nerve to avoid injury to this nerve before entering the floor of the fourth ventricle. A very large variability in size and position of the facial nerve response has been demonstrated, even in patients with a brainstem lesion located far from the facial colliculus. ${ }^{3}$ In the case of a tegmental lesion, intraoperative monitoring of the oculomotor and trochlear nuclei may allow for more accurate and safe surgical removal of the lesion. ${ }^{17}$

\section{Image Guidance for Brainstem Surgery}

Operative image guidance is indispensable in planning approaches and in treating brainstem lesions. The ability to fuse preoperative fine-cut magnetic resonance imaging (MRI) studies with the operating microscope allows the microscopic image to be correlated with the anatomical MRI study. The use of image guidance often directs intraoperative decision making as to the location of the lesion and the boundary of pathology with normal tissues. In cases where the lesion does not abut a pial surface, neuronavigation can assist with the selection of entry points. Recent developments and innovations from combining neuronavigation and microscope technologies have allowed our group to develop automatic positioning of the operating microscope onto a set target with a planned trajectory. ${ }^{30}$ The integration of this automatic microscope positioning has greatly improved operative efficacy and safety.

\section{Surgical Tools for Brainstem Surgery}

Brainstem surgery is necessarily carried out through

ABBREVIATIONS CN = cranial nerve; MCP = middle cerebellar peduncle; MRI = magnetic resonance imaging; SCIT = supracerebellar infratentorial. INCLUDE WHEN CITING Published online September 23, 2016; DOI: 10.3171/2016.6.JNS161043.

* Drs. Kalani and Yagmurlu contributed equally to this work. 
deep, narrow corridors. Because the visual axis and light source of the microscope are $3^{\circ}$ to $6^{\circ}$ apart, depending on the focal length used, the small deep exposure is frequently poorly illuminated. Lighted suction and bipolar devices eliminate this problem. Other innovations in surgical tools that allow surgeons to operate in the brainstem include low-profile bayonetted microinstruments and microdissectors (Fig. 1). The addition of lighted instruments allows the surgeon to use the instrument for illumination in addition to its original intended purpose. A lighted suction device, for example, functions not only as a source of suction but also as a source of illumination and dynamic retraction.

\section{Retractorless Brainstem Surgery}

Proper patient positioning, appropriately sized and placed craniotomies, and microinstruments now obviate the need for retractors in virtually all cases. ${ }^{36}$ The implementation of dynamic retraction using the shaft of the bipolar, suction, or microinstruments allows the surgeon to perform the necessary operation with better visualization and less trauma to the surrounding brain (Fig. 2).

\section{The Two-Point Method}

The two-point method describes a general strategy for selecting an approach that optimally gains access to lesions while minimizing transgression of brain ${ }^{6}$ (Fig. 3). This method can be applied to lesions anywhere in the brain, but it is most commonly used for brainstem lesions when the approach allows entry to the lesion using a pial or an ependymal surface with minimal brain transgression. Using MRI sequences, the neurosurgeon identifies the geometrical center of the lesion and places a point at the center (Point A). A second point (Point B) is identified as the point where the lesion is most superficial or where the entry point defines the safest surgical corridor. A line is then drawn from the first point to the second point and onward to the skull. The trajectory of the line dictates the approach.

As with any simplification of a complex decision strategy, there are caveats to the routine use of the two-point method (Fig. 4). First, the two-point method should be used in the context of defined safe-entry zones; the use of a safe-entry zone may be advantageous relative to simply traversing eloquent brain tissue along a two-point trajectory. An example of this strategy is the resection of a dorsal pontine lesion via the middle cerebellar peduncle (MCP) safe-entry zone that traverses more brain but spares injury to structures in the floor of the fourth ventricle (the trajectory predicted by the two-point method) that would lead to further morbidity. Second, approaches that place the surgeon tangential to the lesion should be avoided because they increase the likelihood of retraction injury during the approach and resection.

\section{Brainstem Safe-Entry Zones}

Safe-entry zones are those points along the brainstem surface where openings are tolerated, because of the sparse nature of eloquent pathways and perforators in these re-

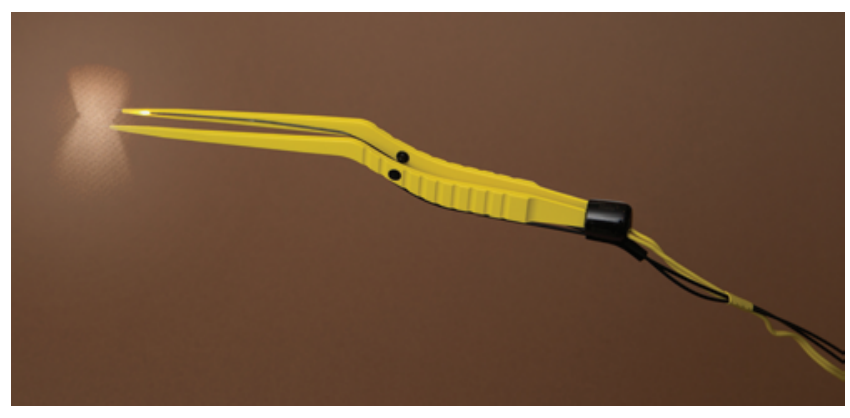

FIG. 1. Bayonetted lighted bipolar forceps. Specialized instruments for resection of deep-seated lesions within the brainstem include bayonetted lighted bipolar forceps, malleable lighted suction devices, and low-profile single-shaft surgical dissectors and forceps that allow the surgeon to operate in a minimally invasive fashion in deep, poorly lit corridors. Copyright Barrow Neurological Institute, Phoenix, Arizona. Published with permission. Figure is available in color online only.

gions, and because access through these zones results in minimal or acceptable morbidity. ${ }^{7,39}$ Fourteen safe-entry zones have been reported for resection of intrinsic brainstem pathology. Surgical approaches to each safe-entry zone are described in Table 1, and approach selection for each safe-entry zone is summarized in Table 2.

\section{Location-Specific Considerations}

\section{Midbrain Pathology}

Generally, we use 3 different surgical routes to reach mesencephalic pathology: anterolateral, posterolateral, and posterior. Three safe-entry zones have been described for resection of intrinsic mesencephalic lesions, depending on the surface of the midbrain that the lesions most closely approximate. Approach selection should simultaneously consider the merits of the two-point method and the available safe-entry zones. For lesions that already abut a pial or an ependymal surface, direct entry into the lesion is naturally least likely to cause further morbidity, often because the pathology has already caused the morbidity that the surgeon was likely to cause by the approach.

\section{Anterolateral Surgical Route}

Our preferred approach for lesions located ventrally in the midbrain and mesencephalopontine junction is the modified orbitozygomatic craniotomy. ${ }^{22}$ We determine an entry zone based on the location of the lesion and displacement of critical structures, which are the intramesencephalic segment of the third cranial nerve (CN III) and the motor fibers (pyramidal tract) in the cerebral peduncle. The intramesencephalic fibers of CN III arise from the oculomotor nuclei and travel medial to and inside the red nucleus to exit the brainstem at the interpeduncular fossa. However, motor fibers (pyramidal tract) are not distributed equally in the cerebral peduncle; the majority travel in the middle three-fifths of the peduncle. The intramesencephalic fibers of CN III and the pyramidal tract may be distorted medially (most commonly) or laterally by the pathology. When the anterior mesencephalic zone (also known as the perioculomotor zone) is used, the brainstem is entered lateral to CN III between the posterior cerebral and superior cerebellar arteries ${ }^{4,5}$ (Fig. 5). Of note, from 


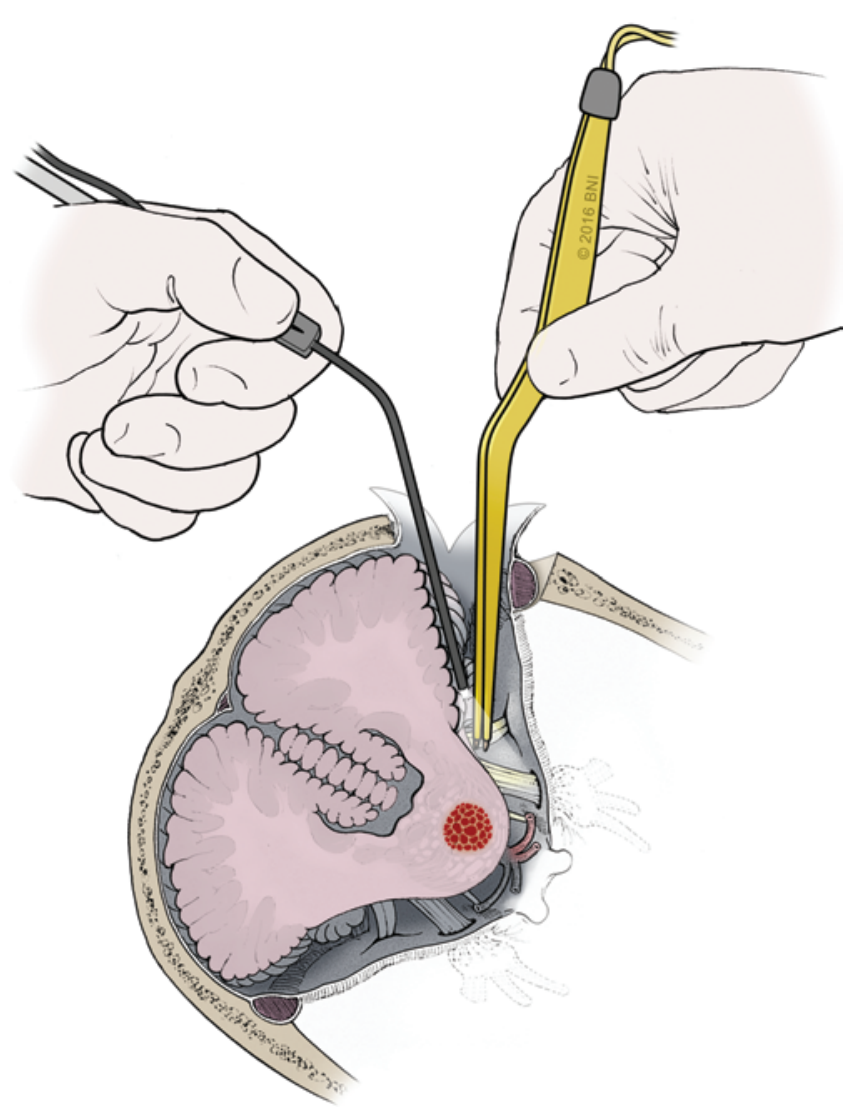

FIG. 2. Dynamic retraction. Unlike the use of fixed systems where bulky retractor systems are used to displace the brain, dynamic retraction allows the surgeon to use the shafts of instruments as mobile retractors. The dynamic nature of the retraction minimizes compression on the brain without sacrifice of the surgical view. Copyright Barrow Neurological Institute, Phoenix, Arizona. Published with permission. Figure is available in color online only.

a technical perspective, after the orbitozygomatic craniotomy is performed, ${ }^{22}$ cerebrospinal fluid is released from the cistern to obtain brain relaxation. The third cranial nerve should be identified and its arachnoid connections should be preserved medially, as sharp dissection is used to detach arachnoid connections of CN III from the temporal lobe or the tentorium. When CN III is followed to the brainstem, an opening between the posterior cerebral and superior cerebellar arteries is well tolerated.

When using this safe-entry zone, it is advisable to leave the medial arachnoid adhesions of CN III intact so that the nerve will not be laterally mobile and injured during the approach. Alternatively, the surgeon may make use of the sparse density of motor fibers in the medial-most onefifth of the cerebral peduncle to enter the brainstem. In this approach, CN III is again used to trace the path back to the brainstem, but instead of disconnecting the lateral arachnoid adhesions to the temporal lobe and tentorium to mobilize CN III, the surgeon should dissect the medial arachnoid adhesions of the nerve to allow it to remain attached laterally. The choice of approach depends on the relation of the brainstem to the clivus and posterior clinoid and on where the lesion is closest to the surface of the brainstem.

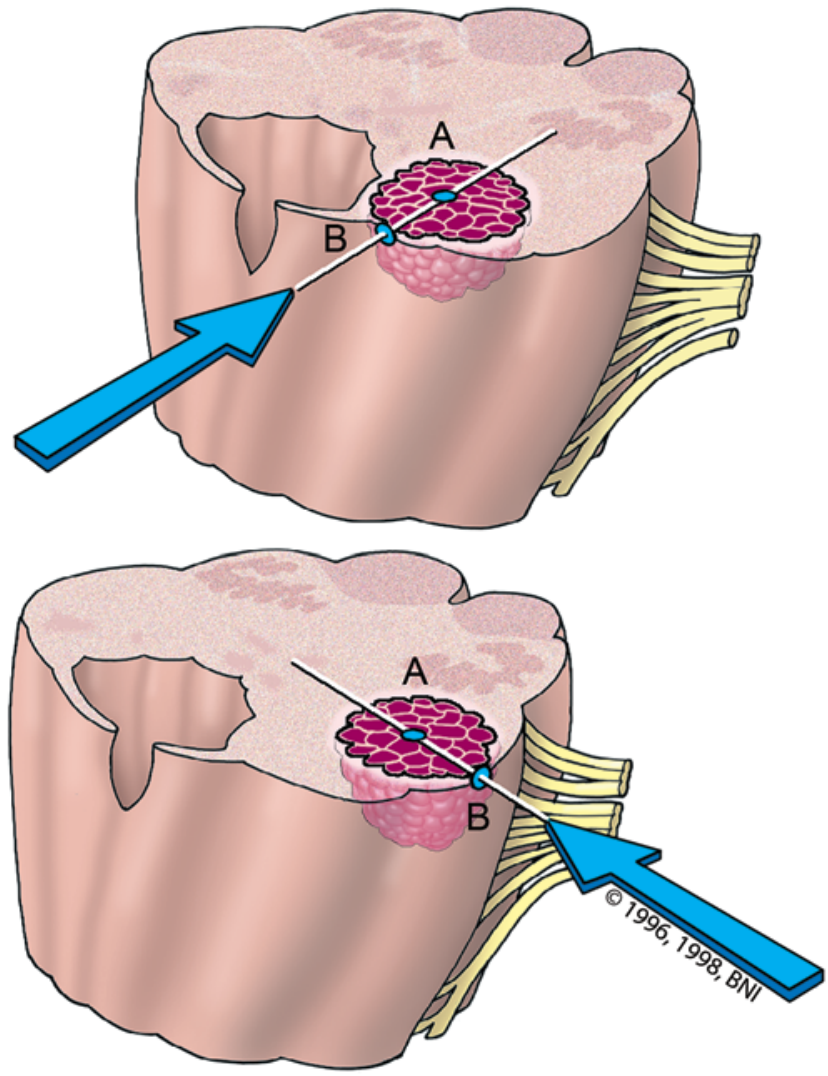

FIG. 3. The two-point method, which is used to guide surgical approach selection for deep-seated lesions. The surgeon places a point at the center of the lesion (Point A). A second point (Point B) is selected where the lesion most closely approximates a pial or an ependymal surface. $A$ straight line is drawn from Point $A$ to Point $B$ and then extended to the skull. This line defines the optimal trajectory for approaching the lesion. Copyright Barrow Neurological Institute, Phoenix, Arizona. Published with permission. Figure is available in color online only.

\section{Posterolateral Surgical Route}

We prefer the lateral or extreme lateral supracerebellar infratentorial (SCIT) approach to reach lesions located laterally in the midbrain. Lesions in this location can be approached using the lateral mesencephalic sulcus safe-entry zone (Fig. 6). The lateral mesencephalic sulcus, which is the border between the crus cerebri and tegmentum on the lateral surface of the midbrain, has been proposed as a safe-entry zone. This sulcus corresponds to the lateral edge of the medial lemniscus, which is a tract that is relatively tolerant of manipulations in the brainstem. This sulcus separates the peduncular and tegmental surfaces of the brainstem and can be readily identified intraoperatively using the trochlear nerve and branches of the superior cerebellar artery that travel adjacent to it. For dorsolateral lesions, a lateral SCIT approach is generally sufficient to expose the lesion. ${ }^{9,19}$ For ventrolateral lesions, an extreme lateral SCIT approach is necessary.

We have abandoned the routine use of subtemporal or anterior petrosectomy approaches for ventrolateral lesions in the brainstem, given the risk of injury to the vein of Labbé and the temporal lobe. The extreme lateral variant allows the surgeon to access the cerebellopontine angle 

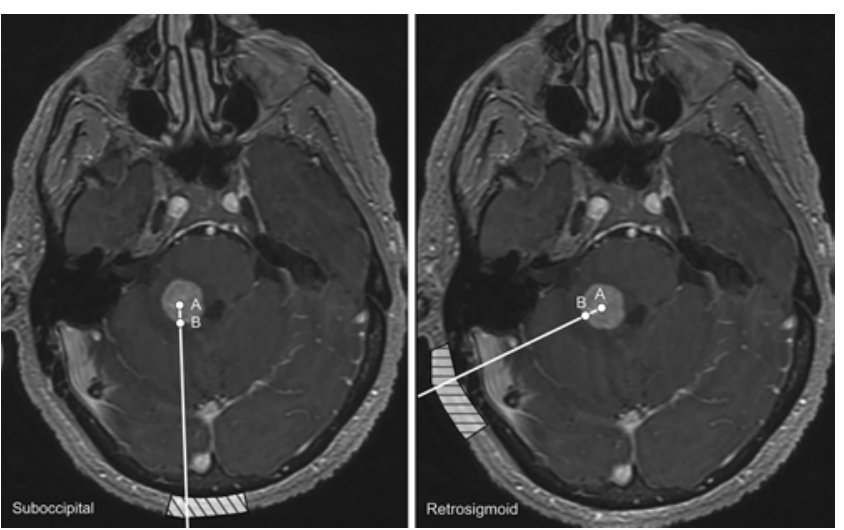

FIG. 4. Application of the two-point method with selection of an alternative, safer corridor. Left: Axial contrast-enhanced T1-weighted MR image demonstrating a lesion in the middle cerebellar peduncle that most closely approximates a pial surface at the floor of the fourth ventricle. The two-point method would suggest that this lesion should be approached using a suboccipital craniotomy. However, a suboccipital craniotomy may place nuclei at the floor of the fourth ventricle at unnecessary risk. Instead, this lesion is best reached using the retrosigmoid approach through the middle cerebellar peduncle safeentry zone. Right: Axial contrast-enhanced T1-weighted MR image demonstrating the middle cerebellar peduncle safe-entry zone and the approach for this lesion. The surgeon should combine the two-point method with knowledge of established safe-entry zones to select the approach that minimizes morbidity risk. In both images the shaded hatched area indicates the craniotomy and the white line indicates the approach derived from the application of the method used.

cistern for cerebrospinal fluid release, which can greatly facilitate the operation. The lateral location of the SCIT craniotomy makes use of the angle of the tentorium to minimize retraction of the cerebellum. For high-riding lesions, the tentorium can be coagulated and incised to lift the mesial structures and obtain the necessary angle to remove the high component of the lesion. ${ }^{18}$ For low-riding lesions, the quadrangular lobule of the cerebellum can be vertically incised to better expose the pontomesencephalic fissure. The key to successful use of the SCIT approach is wide arachnoidal opening of the ambient cistern, allowing the cerebellum to fall away.

\section{Posterior Surgical Route}

To reach the dorsal midbrain, we prefer the midline
TABLE 2. Accessible safe-entry zone by surgical approach

\begin{tabular}{ll}
\hline \multicolumn{1}{c}{ Approach } & \multicolumn{1}{c}{ Safe-Entry Zone } \\
\hline Orbitozygomatic & AMZ \\
\hline Subtemporal & AMZ \\
\hline Subtemporal transtentorial & AMZ, STZ \\
\hline Anterior petrosectomy & AMZ, STZ, PTZ \\
\hline Suboccipital w/ or w/o telovelar & MS, SF \\
\hline Median SCIT & LMS, IC, SC, IF \\
\hline Lateral/extreme lateral SCIT & LMS, IC, SC, IF \\
\hline Retrosigmoid & LMS, STZ, PTZ, LPZ, AL, PM, LMZ \\
\hline Far lateral & AL, PM, LMZ, olivary \\
\hline Retrolabyrinthine & LMS, STZ, PTZ, LPZ, AL, PM, LMZ, \\
& olivary \\
\hline
\end{tabular}

$\mathrm{AL}=$ anterolateral sulcus of medulla; $\mathrm{AMZ}=$ anterior mesencephalic zone; $\mathrm{IC}$ = intercollicular; IF = infracollicular; LMS = lateral mesencephalic sulcus; LMZ = lateral medullary zone; $\mathrm{LPZ}=$ lateral pontine zone; $\mathrm{MS}=$ median sulcus of fourth ventricle; $\mathrm{PM}=$ posterior median sulcus of the medulla; $\mathrm{PTZ}=$ peritrigeminal zone; SC = supracollicular; SCIT = supracerebellar infratentorial; SF = superior fovea; STZ = supratrigeminal.

SCIT approach (Fig. 7). If the lesion allows the surgeon to move to a more lateral position, the surgeon may be able to more readily mobilize the cerebellum and make use of the less steep angle of the tentorium. The key to developing the potential supracerebellar space is generous disconnection of the arachnoid bands around the vein of Galen and laterally along the vein of Rosenthal. Although every effort is made to preserve the cerebellar vein, sacrifice of a vein may improve visualization and exposure of the quadrigeminal plate.

The intercollicular safe-entry zone is likely to result in less morbidity than the supracollicular and infracollicular safe-entry zones. Although the colliculi are involved in visual and auditory stimulus processing, the intercollicular region is sparse in fibers. The colliculi can be readily identified intraoperatively as round eminences on the dorsal midbrain surface.

\section{Pontine Pathology}

We use the posterolateral and posterior surgical routes to reach the majority of pontine lesions. The posterolateral route is via the retrosigmoid approach for ventral pontine

TABLE 1. Surgical approaches to the brainstem

\begin{tabular}{clll}
\hline Lesion Location & \multicolumn{1}{c}{ Anterior Approach } & Lateral Approach & Posterior Approach \\
\hline Midbrain & $\begin{array}{c}\text { Pterional w/ or w/o orbitozygomatic } \\
\text { osteotomies }\end{array}$ & $\begin{array}{c}\text { Anterolateral: pterional w/ or w/o orbitozygo- } \\
\text { matic osteotomies } \\
\text { Posterolateral: paramedian or extreme } \\
\text { lateral supracerebellar infratentorial }\end{array}$ & $\begin{array}{c}\text { Median supracerebellar } \\
\text { infratentorial }\end{array}$ \\
\hline Pons & Pterional w/ or w/o orbitozygomatic \\
& osteotomies & Retrosigmoid & Suboccipital telovelar \\
& $\begin{array}{c}\text { Subtemporal w/ or w/o transtentorial } \\
\text { extension } \\
\text { Retrolabyrinthine }\end{array}$ & & Suboccipital \\
& Retrosigmoid & & \\
& Far lateral & & \\
\hline Medulla & Retrosigmoid & Far lateral & Suboccipital telovelar \\
& & Retrosigmoid & Suboccipital \\
\hline
\end{tabular}



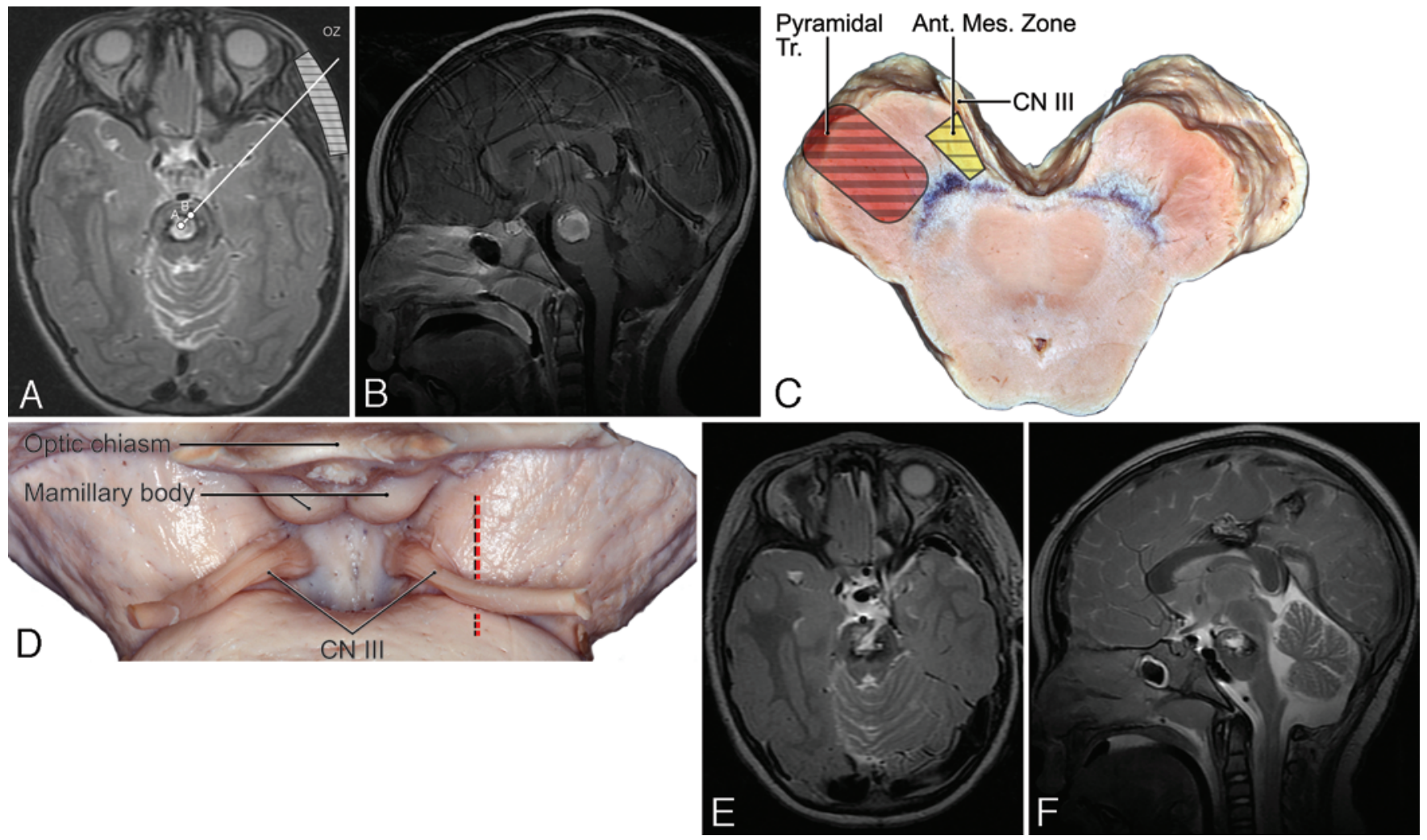

FIG. 5. Approach for a lesion in the ventral midbrain/pons. Representative case of a 3-year-old girl who presented with sudden-onset right-sided hemiparesis and palsies of the right third, sixth, and seventh cranial nerves. Axial T2-weighted (A) and sagittal T1weighted (B) MR images demonstrate a large pontomesencephalic cavernous malformation with evidence of acute hemorrhage. The two-point method suggests that this lesion should be approached using a ventrolateral approach (A, white line). Instead, the lesion was approached using a modified-orbitozygomatic (OZ) craniotomy. Because the lesion does not reach a pial surface, the best route for entry is a safe-entry zone that minimizes the surgeon's footprint. The anterior mesencephalic (Ant. Mes.) zone (C, right hatched area) is a defined safe-entry zone in the ventral midbrain that can be used to access deep-seated lesions in the midbrain. This safe-entry zone makes used of the sparse nature of motor fibers in the midbrain to gain entry into the brainstem. The left hatched area demonstrates the pyramidal tract (Tr.). This safe-entry zone (D, dashed line) is located lateral to CN III and between the posterior cerebral and superior cerebellar arteries. Postoperative axial $(\mathbf{E})$ and sagittal $(\mathbf{F})$ T2-weighted MR images demonstrate complete removal of the lesion. The patient was neurologically stable postoperatively. Panel $\mathrm{C}$ and $\mathrm{D}$ dissections prepared by Kaan Yagmurlu, MD. Reproduced with permission from the Rhoton Collection (http://rhoton.ineurodb.org), CC BY-NC-SA 4.0 (http://creativecommons.org/licenses/by-nc-sa/4.0). Figure is available in color online only.

lesions, and the posterior route is via the suboccipital midline approach (with opening of the telovelar junction for select cases) for dorsal pontine lesions. Seven safe-entry zones have been described for resection of intrinsic pontine lesions, depending on the surface of the pons that the lesion most closely approximates. Given that the ventral pons is not readily accessible and that there is a rich array of motor fibers that traverse this surface, the majority of approaches to pontine pathology make use of lateral or posterior surgical routes. The dorsal surface of the pons constitutes part of the floor of the fourth ventricle, and this surface is less forgiving than the lateral pontine surface. In the selection of surgical approaches to the pons, the eloquent nature of the floor of the fourth ventricle must be a primary consideration. Again, approach selection should simultaneously consider the merits of the two-point method and the various safe-entry zones. For lesions that protrude into a cerebrospinal fluid pathway or abut a pial or an ependymal surface (e.g., exophytic fourth ventricular lesions), direct entry using the floor of the fourth ventricle may be appropriate.

\section{Posterolateral Surgical Route}

A retrosigmoid approach provides a lateral route to the ventral pons. The size of the retrosigmoid craniotomy need not be excessively large, but the craniotomy should expose the transverse and sigmoid sinuses (and their junction) so that the sinus may be retracted using sutures. Extension of the patient's head toward the floor improves visualization of lesions that are located at or extend to the pontomesencephalic junction. In general, the petrosal vein complex should be preserved and mobilized when necessary. The arachnoid membrane overlying the cranial nerves should be preserved to prevent injury.

The pons is optimally entered using 1 of the 3 lateral safe-entry zones. These areas allow the surgeon to resect deep-seated lateral and ventral pontine lesions. The peritrigeminal zone describes an area lateral to the corticospinal tract and anterior to the motor and sensory nuclei of the trigeminal nerve. When selecting this safe-entry zone, the surgeon should ensure preservation of the intrapontine fibers of CN VI, CN VII, and CN VIII, which travel in an anteroposterior direction. As dissection deepens using this 

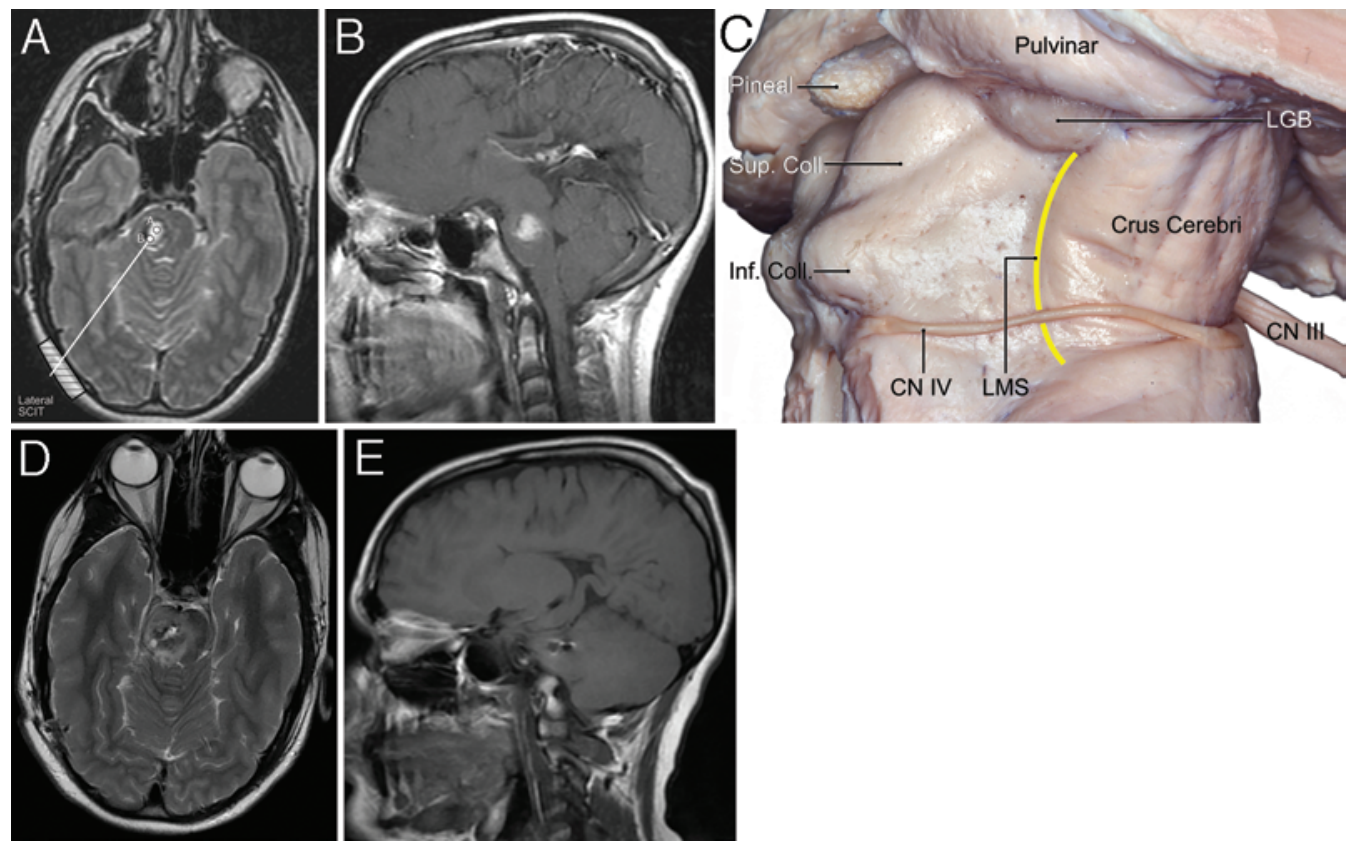

FIG. 6. Approach for lesions in the lateral midbrain and pontomesencephalic region. Representative case of a 12-year-old boy who presented with sudden-onset left-sided paresthesias, weakness, and imbalance. Axial T2-weighted (A) and sagittal T1-weighted (B) MR images demonstrate a large lateral pontomesencephalic cavernous malformation with evidence of acute hemorrhage. The two-point method ( $A$, white line) suggests that this lesion should be approached using a dorsolateral approach. This lesion was approached using a lateral SCIT craniotomy (A, shaded hatched area). Because the lesion did not reach a pial surface, the lateral mesencephalic sulcus safe-entry zone was used for entry to the lesion. The lateral mesencephalic sulcus (LMS) separates (C, curved line) the peduncular and tegmental surfaces of the midbrain and extends caudally in a concave fashion from the medial geniculate body to the pontomesencephalic sulcus. The $\mathrm{P}_{2}$ segment of the posterior cerebral artery and medial posterior choroidal artery, the cerebellomesencephalic segment of the superior cerebellar artery, and the trochlear nerve cross the sulcus. Postoperative axial T2-weighted (D) and sagittal T1-weighted (E) MR images demonstrate complete removal of the lesion. The patient experienced a new left CN VI palsy postoperatively. Coll. = colliculus; Inf. = inferior; LGB = lateral geniculate body; Sup. = superior. Panel C dissection prepared by Kaan Yagmurlu, MD. Reproduced with permission from the Rhoton Collection (http://rhoton. ineurodb.org), CC BY-NC-SA 4.0 (http://creativecommons.org/licenses/by-nc-sa/4.0). Figure is available in color online only.

safe-entry zone, injury to the trigeminal nuclei is possible. Alternatively, the supratrigeminal safe-entry zone may be used for lesions located rostral to $\mathrm{CN} \mathrm{V}$. The workhorse safe-entry zone used at our institution, however, is the $\mathrm{MCP}$ or the lateral pontine safe-entry zone. This zone is located between $\mathrm{CN}$ V and the CN VII-VIII complex. All 3 zones are approached using a retrosigmoid craniotomy. The MCP safe-entry zone is exposed by dissecting the petrosal fissure using a technique akin to splitting the sylvian fissure ${ }^{20}$ (Fig. 8). This simple maneuver allows the surgeon to obtain a more direct and shallow exposure of the MCP. The neurotomy in the MCP is placed sharply using scissors on the surface devoid of veins. In general, we favor expanding the opening in the brainstem by using microforceps to stretch the fibers parallel to the ascending and descending fibers. We have largely abandoned the use of the subtemporal, anterior petrosectomy, retrolabyrinthine, or combined supratentorial and infratentorial approaches to reach ventral or ventrolateral pontine lesions.

\section{Posterior Surgical Route}

In general, 4 safe-entry zones may be used to resect dorsal pontine lesions that do not abut a pial surface. The suprafacial collicular zone, infrafacial collicular zone, median sulcus above the level of the facial colliculus, and superior fovea triangular zone are the defined safe-entry zones dorsally on the pons. The suprafacial collicular zone is demarcated laterally by the sulcus limitans, medially by the medial longitudinal fascicle, rostrally by the frenulum veli, and caudally by the facial colliculus. The infrafacial collicular zone is demarcated laterally by the facial nucleus, medially by the medial longitudinal fasciculus, rostrally by the facial colliculus, and caudally by the hypoglossal triangle. Alternatively, the medial sulcus of the fourth ventricle, which is located between the projections of the $\mathrm{CN}$ VI nuclei on the surface and the projections of the CN III nuclei on the midbrain surface, can be used as a safe-entry zone. More recently, we have described approaching lesions at the level of the facial colliculus using the superior fovea (Yagmurlu K, Kalani MYS, Preul MC, Spetzler RF: The superior fovea triangle approach: A novel safe entry zone to the brainstem, unpublished). The key to resecting deep lesions in the dorsal pons or floor of the fourth ventricle is to avoid the midline when possible, even if by only a few millimeters, to minimize damage to the unforgiving structures in the midline floor of the fourth ventricle (Fig. 9). This may require approaching a dorsal pontine lesion using the MCP safe-entry zone via a longer trajectory of approach to minimize manipulation of structures in the floor of the fourth ventricle. To approach dorsal pontine le- 

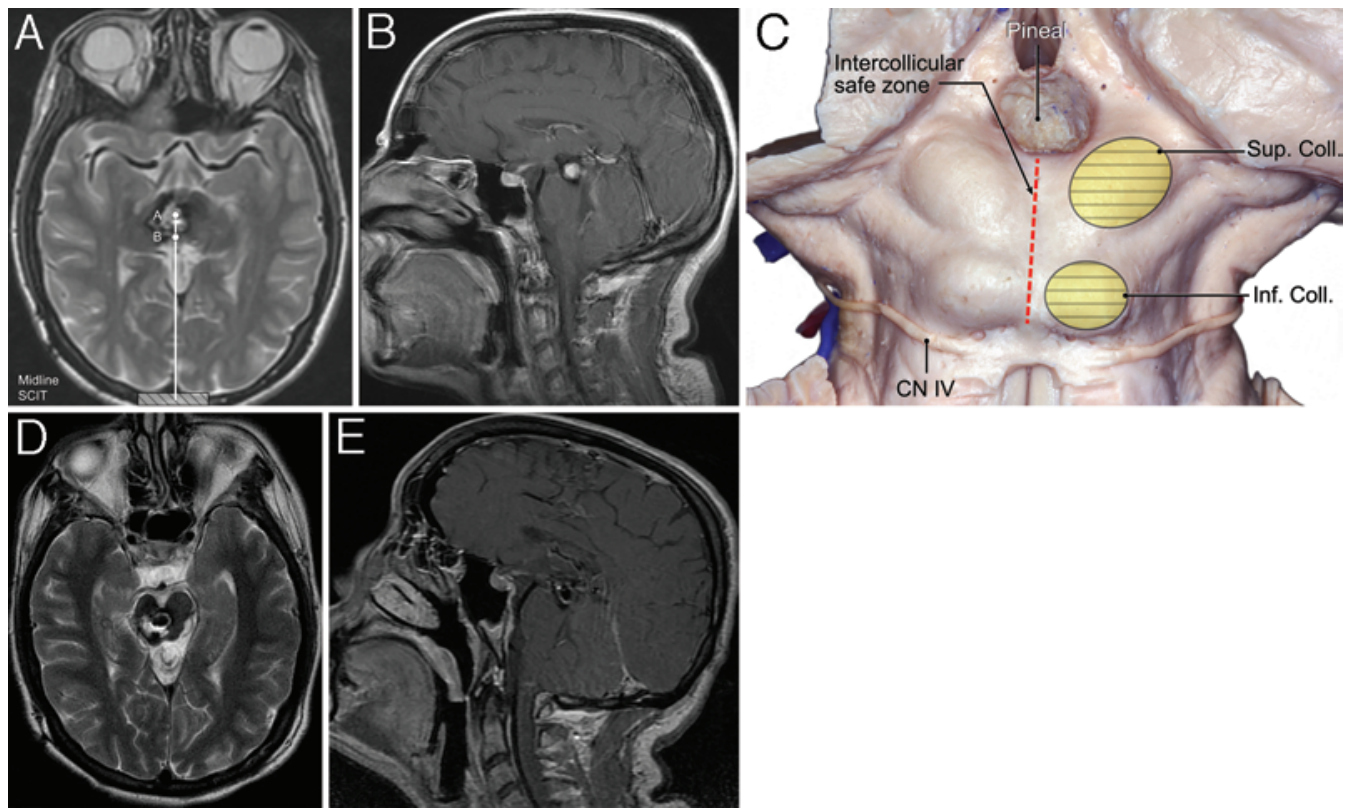

FIG. 7. Approach for a lesion in the dorsal midbrain. Representative case of a 34-year-old woman who presented with suddenonset left-sided weakness and diplopia. Axial T2-weighted (A) and sagittal T1-weighted (B) MR images demonstrate a dorsal mesencephalic cavernous malformation. The two-point method ( $A$, white line) suggests that this lesion should be approached using a midline dorsal approach. This lesion was approached using a midline SCIT craniotomy (A, shaded hatched area). In this case, the lesion did reach a pial surface, but, if it had not, the lesion would still have been accessed using the intercollicular safe-entry zone (C, dashed line). The colliculi ( $\mathrm{C}$, hatched areas) are readily apparent on the dorsal surface of the brainstem. The key to the use of this operation is avoidance of injury to the deep venous circulation. Postoperative axial T2-weighted (D) and sagittal T1-weighted (E) MR images demonstrate complete removal of the lesion. The patient was neurologically stable postoperatively. Panel $\mathrm{C}$ dissection prepared by Kaan Yagmurlu, MD. Reproduced with permission from the Rhoton Collection (http://rhoton.ineurodb.org), CC BY-NC-SA 4.0 (http://creativecommons.org/licenses/by-nc-sa/4.0). Figure is available in color online only.

sions, we use a midline suboccipital approach. For lesions located lateral to the midline, a modified telovelar suboccipital approach can be used. Opening the tela and velum and exposing the foramen of Luschka allow the surgeon to laterally enter the dorsal pons. In general, the patient is positioned prone with the neck flexed and the chin tucked. For lesions located at the level of the pontomesencephalic junction, the neck must be maximally flexed and removal of the arch of C-1 may be necessary to obtain the angle of attack needed to reach the pathology.

\section{Medullary Pathology}

Four safe-entry zones have been described for resection of intrinsic medullary lesions. Similar to the ventral pons, the ventral medulla is not readily accessible, and most approaches to this region make use of a lateral or dorsal approach. As mentioned above, the dorsal surface of the pons constitutes part of the floor of the fourth ventricle, and this surface is less forgiving than the lateral surface.

\section{Posterolateral Surgical Route}

Ventral medullary lesions may be accessed by using the anterolateral sulcus safe-entry zone. This is accomplished by obtaining a low approach and opening the arachnoid between the lower cranial nerves and the fibers of the C-1 nerve root. In this region, the fibers of the corticospinal tract decussate, allowing entry into the medulla with minimal morbidity. Alternatively, the surgeon may access the lateral medulla using the olivary zone. This zone is located between the anterolateral sulcus and pyramids anteriorly and by the posterolateral sulcus posteriorly. These 2 safeentry zones are often accessed using a far-lateral approach, although more recently we have modified our technique and can access these regions from a low retrosigmoid craniotomy. The workhorse approach for resecting ventral and ventrolateral medullary lesions at our institution is via the lateral medullary zone through the inferior cerebellar peduncle $^{10}$ (Fig. 10). With a retrosigmoid approach, the arachnoid between the lower cranial nerve complex and the $\mathrm{CN}$ VII-VIII complex is opened and exposure is carried out to visualize the foramen of Luschka. A small vertical incision is made in the inferior cerebellar peduncle below the cochlear nuclei and posterior to the origin of the lower cranial nerves. Exposure of the arachnoid over the CN VII-VIII complex and lower cranial nerves is often unnecessary.

\section{Posterior Surgical Route}

This route is provided by the suboccipital midline approach, with or without removal of the C-1 posterior arch. Lesions in the dorsal medulla can be accessed using the posterior median, posterior intermediate, or posterior lateral sulci safe-entry zone (Fig. 11). This zone is bound superiorly by the obex and laterally by the clava. In a manner similar to opening the midline sulcus of the spinal cord posteriorly, the medulla can be entered and intrinsic lesions resected from this region. Lesions deep to the calamus scriptorius should be approached laterally to avoid injury to the dorsally located nuclei of the lower cranial nerves. 


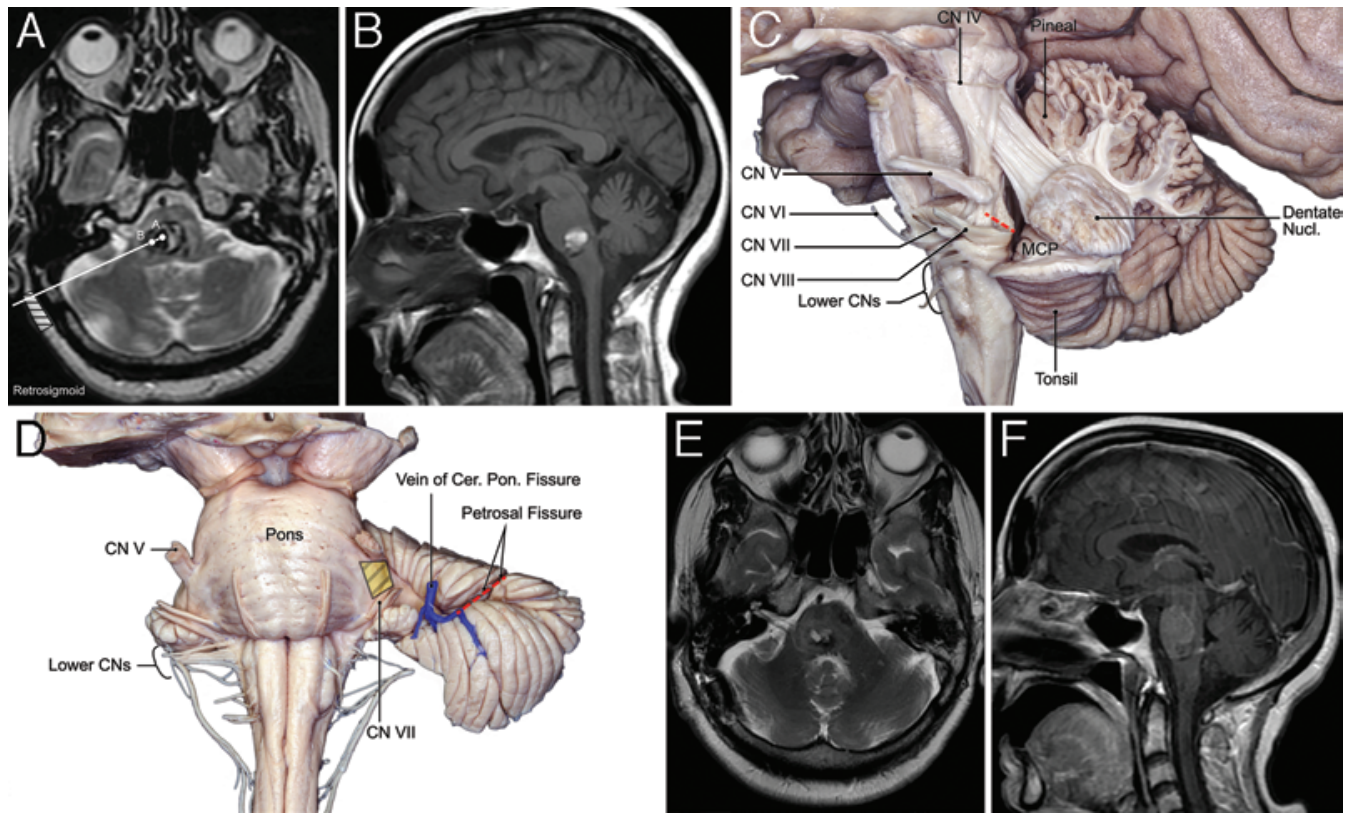

FIG. 8. Approach for lesions in the lateral pons and pontomedullary junction. Representative case of a 56-year-old woman who presented with sudden-onset diplopia, left upper-extremity paresthesias, and left lower-extremity weakness. Axial T2-weighted (A) and sagittal T1-weighted (B) MR images demonstrate a lateral pontomedullary cavernous malformation. The two-point method suggests that this lesion should be approached using a lateral approach ( $A$, white line). This lesion was approached using a retrosigmoid craniotomy (A, shaded hatched area). This lesion did not abut a pial surface and was approached using the middle cerebellar peduncle (MCP) safe-entry zone ( $\mathbf{C}$, dashed line). Although several safe-entry zones, including the peritrigeminal, supratrigeminal, and lateral pontine zone, have been described, we prefer to approach lesions in the pons and high pontomedullary junction lesions using the more posteriorly located MCP safe-entry zone (C). Once cerebrospinal fluid is released from the cerebellopontine cistern, the petrosal fissure extending into the lateral apex of the cerebellopontine angle is identified and split using microsurgical technique. The fissure can be readily identified using the vein of the cerebellopontine fissure and branches of the anterior inferior cerebellar artery running along or in the fissure (D; hatched area defines this safe-entry zone). Postoperative axial T2-weighted $(\mathbf{E})$ and sagittal T1-weighted $(\mathbf{F})$ MR images demonstrate complete removal of the lesion. The patient experienced transient worsening of symptoms and developed a new right CN VI palsy but her condition subsequently improved to her preoperative examination status. Cer. = cerebellar; Nucl. = nucleus; Pon. = pontine. Panel $\mathrm{C}$ and $\mathrm{D}$ dissections prepared by Kaan Yagmurlu, MD. Reproduced with permission from the Rhoton Collection (http://rhoton.ineurodb.org), CC BY-NCSA 4.0 (http://creativecommons.org/licenses/by-nc-sa/4.0). Figure is available in color online only.

\section{General Technique for Resection of Well-Encapsulated Lesions}

In general, after performing the approach to arrive upon the brainstem surface, we vertically open a pial or an ependymal brainstem surface, parallel to the fibers at the level of the safe-entry zone, using bayonet microforceps instead of a blade. The opening of the forceps is used to stretch and displace fibers to allow the surgeon to reach the lesion. After exposure of the lesion, we use micropituitary forceps, dissectors, suction, and cautery to remove the lesion in a piecemeal fashion. In cases of cavernous malformations, the gliotic tissue surrounding the cavernous malformation and the developmental venous anomaly should be preserved. After complete removal of the lesion, hemostasis is achieved using electrocautery on a low setting. Alternatively, hemostatics may be placed into the resection cavity to assist with hemostasis but should be removed upon completion of the procedure.

\section{Discussion}

The most common of the surgically accessible brainstem lesions are cavernous malformations and juvenile pilocytic astrocytomas. The estimated prevalence of cavernous malformations in the population is approximately $0.4 \%-0.8 \%$, with approximately $40 \%$ of these lesions discovered incidentally. ${ }^{25,26,29,31,34,35,38}$ Prospective observation has indicated an overall symptomatic rate of hemorrhage of $0.2 \%-0.7 \%$ per year for such lesions..$^{15,27,34}$ However, retrospective analysis of patients with cavernous malformations has yielded a calculated average symptomatic hemorrhage rate of $2.7 \%-5 \%$ and a rehemorrhage rate of $21 \%-60 \%$ per year and per lesion. ${ }^{1,13,21,26,28,33}$ This hemorrhage rate may be even higher for lesions located in the brainstem. Hemorrhage from a cavernous malformation can have diverse consequences, ranging from remaining completely asymptomatic to causing death. In our practice, we prefer microsurgical treatment as a first modality in symptomatic patients or in those who have had at least 1 episode of hemorrhage and have an accessible lesion. ${ }^{2}$

Several groups have demonstrated safety and efficacy of surgical removal of cavernous malformations in the brainstem. Dukatz et al. ${ }^{11}$ reported on a series of 71 patients with brainstem cavernous malformations that were surgically treated. After surgical intervention, $63 \%$ of the patients showed improvement in Karnofsky Performance Scale status, $27 \%$ showed no change, and $11 \%$ showed deterioration. 

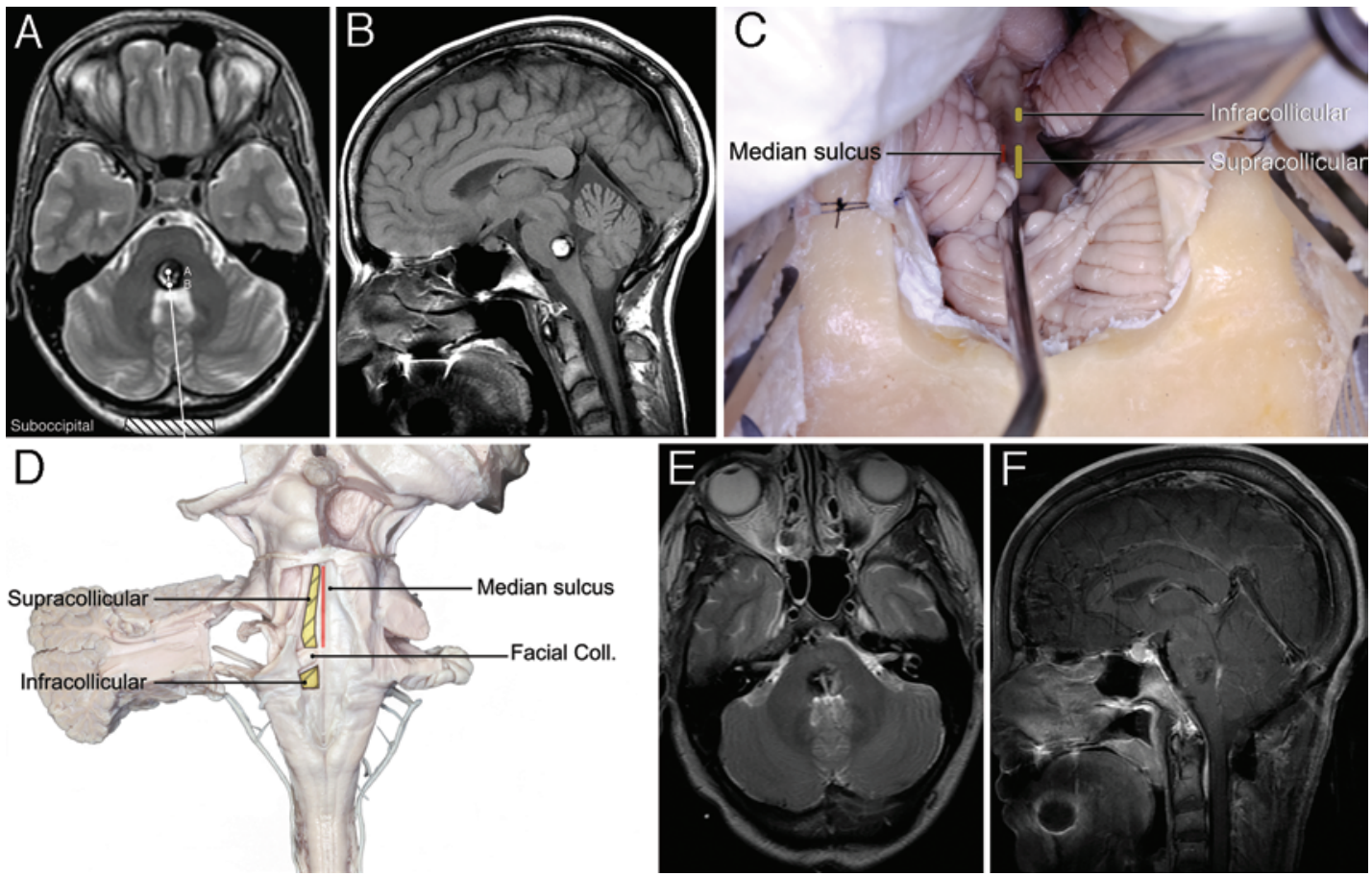

FIG. 9. Approach for a dorsal pontine lesion. Representative case of a 44-year-old woman who presented with intermittent vertigo. Axial T2-weighted (A) and sagittal T1-weighted (B) MR images demonstrate a dorsal pontine cavernous malformation that abuts a pial plane at the floor of the fourth ventricle. The two-point method suggests that this lesion should be approached using a posterior midline approach ( $\mathrm{A}$, white line). This lesion was approached using a suboccipital craniotomy ( $\mathrm{A}$, shaded hatched area). Three safe-entry zones have been described for exposure of lesions in the dorsal pons (C). These include the supracollicular and infracollicular zones and the median sulcus of the fourth ventricle above the level of the facial colliculus. Given that this lesion arrived at a pial surface, we approached the lesion directly. Alternatively, if the lesion is deep, our preference is to expose the lesion using the median sulcus of the fourth ventricle above the level of the facial colliculus or more laterally to minimize injury to nuclei that reside in the floor (D; hatched areas show safe-entry zones). For lesions located lateral to the midline, a modified telovelar suboccipital approach can be used. Postoperative axial T2-weighted (E) and sagittal T1-weighted (F) MR images demonstrate complete removal of the lesion. The patient experienced transient new left CN III and CN VII palsies but ultimately improved to her preoperative examination status. Panel $\mathrm{C}$ and D dissections prepared by Kaan Yagmurlu, MD. Reproduced with permission from the Rhoton Collection (http://rhoton.ineurodb.org), CC BY-NC-SA 4.0 (http://creativecommons.org/licenses/by-nc-sa/4.0). Figure is available in color online only.

Abla et al. ${ }^{1}$ documented the long-term durability of surgical treatment of brainstem cavernous malformations with patient outcomes and clinical complications in 260 patients from our institution. They noted that despite longterm improvements, the majority of patients $(53 \%)$ developed new deficits or worsening of preexisting deficits postoperatively; $36 \%$ of the patients developed new permanent deficits. These significant rates of new or worsened deficits highlight the importance of careful patient selection and a thorough discussion with patients about the expected postoperative course, especially early in the surgeon's experience.

In a series of 176 patients with cavernous malformations located in the brainstem, thalamus, and basal ganglia, the Stanford group noted an $11.2 \%$ rate of new permanent deficits at last follow-up. ${ }^{32}$ In that series, $68.8 \%$ of the patients (121 of 176) suffered no new deficits postoperatively, and at last follow-up 61.8\% (105 of 170) had improvement in their condition and $25.9 \%$ (44 of 170) had no change after intervention.

Garcia et al ${ }^{14}$ reported their preoperative clinical and imaging predictors of microsurgical outcomes in 104 patients with brainstem cavernous malformations. In their case series, the mortality was $0.96 \%(\mathrm{n}=1)$. Worsening cranial nerve or motor function was noted in $14.4 \%$ ( $\mathrm{n}=$ 15), and an increase in modified Rankin Scale scores was noted in $9.6 \%(\mathrm{n}=10)$.

Li et al. ${ }^{23}$ reviewed their experience with resection of brainstem cavernous malformations in 242 patients. They noted that one-third $(n=85)$ of the patients demonstrated worsened condition immediately after surgery but recovered to their baseline level within 3-6 months of surgery. With respect to long-term outcome (mean follow-up $89.4 \pm$ 4 months), the authors reported that permanent morbidity was evident in $26.9 \%(n=65)$ of the patients.

In another study, Gross et al. ${ }^{16}$ reviewed published data from 1390 cases of brainstem cavernous malformations to analyze the risk and benefits related to resection of these lesions. The rate of complete excision was 91\% (1178 of 1291), the rehemorrhage rate associated with partial resection was $62 \%$ (65 of 105), and the early rate of neurological morbidity was $45 \%$ (425 of 944). Most (62\% [609 of 987]) of the patients had improvement of their symptoms over the long term, and the rate of mortality was $1.5 \%$ (21 of 1390).

Gliomas of the brainstem comprise $1.4 \%$ of all intracra- 

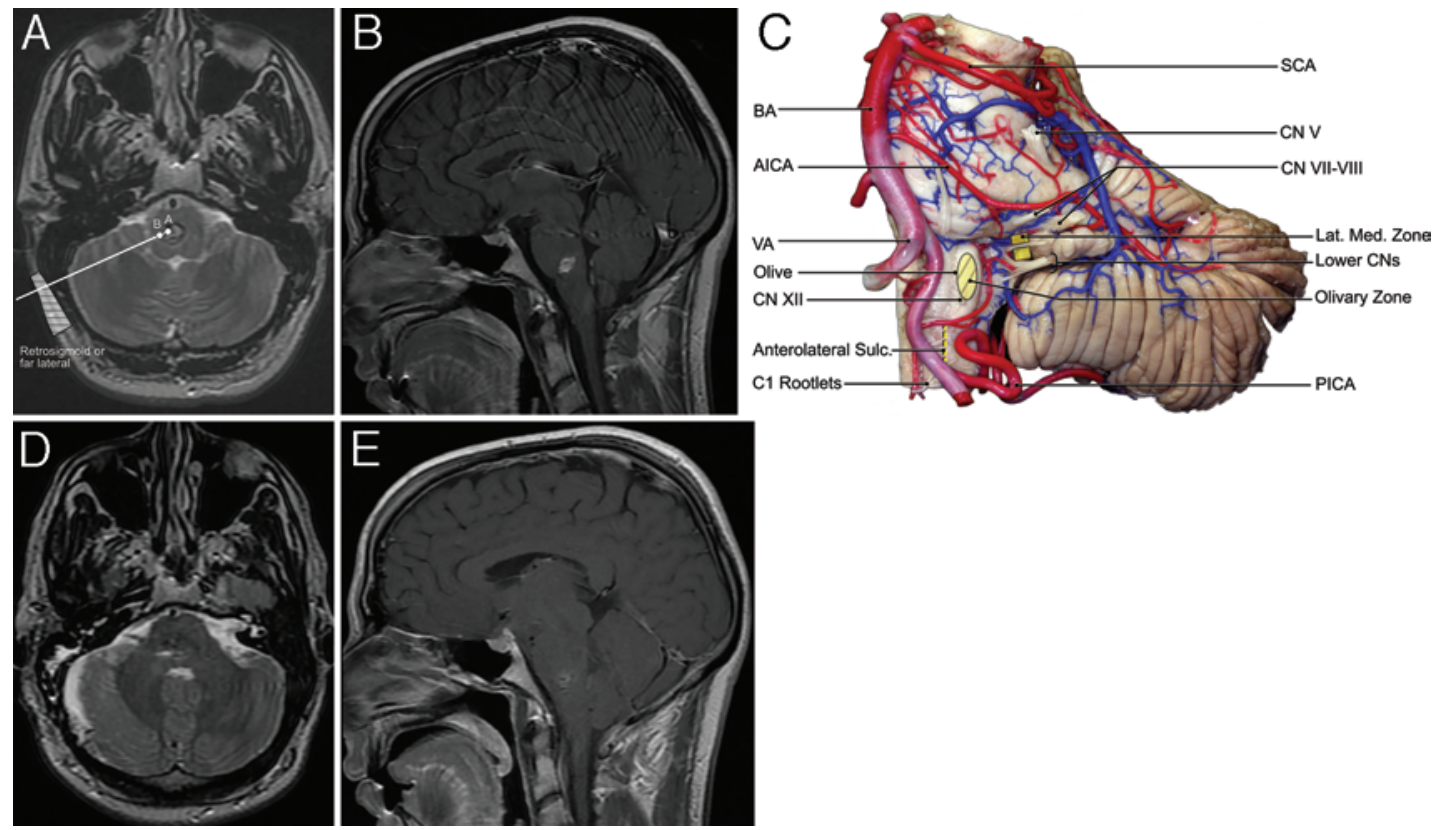

FIG. 10. Approach for ventral and ventrolateral medullary and pontomedullary lesions. Representative case of a 33-year-old man who presented with left-sided whole-body numbness. Axial T2-weighted (A) and sagittal T1-weighted (B) MR images demonstrate a deep laterally located pontomedullary cavernous malformation that does not abut a pial plane. The two-point method suggests that this lesion should be approached using a lateral approach ( $\mathrm{A}$, white line). This lesion was approached using a low retrosigmoid craniotomy ( $A$, shaded hatched area), although it could have also been reached using a far-lateral approach. For lesions located lower in the medulla, a far-lateral craniotomy may be necessary. Safe-entry zones used for exposure of lesions in the ventral and ventrolateral medulla include the anterolateral sulcus (Sulc.), the olivary zone, and the lateral medullary zone (Lat. Med.) (C; shaded and hatched areas define safe-entry zones). The anterolateral sulcus safe-entry zone makes use of the decussation of the corticospinal tract between the rootlets of the hypoglossal nerve and the C-1 spinal nerve as a point of entry. Similarly, at the level of the olives on the anterolateral surface of the medulla, a safe-entry zone limited medially by the anterolateral sulcus and the pyramids, and posteriorly by the posterolateral sulcus, can be used to enter the medulla for deep lesions that do not arrive at a pial surface. The preferred safe-entry zone at our institution is the lateral medullary zone via the inferior cerebellar peduncle. The inferior cerebellar peduncle is approached between the lower cranial nerves and the CN VII-VIII complex. Direct ventral approaches to the medulla are challenging and pose significant risks to the patient, and thus our preference is to approach ventral and ventrolateral lesions from the side using either the retrosigmoid or the far-lateral craniotomy. Postoperative axial T2-weighted (D) and sagittal T1-weighted (E) MR images demonstrate complete removal of the lesion. The patient experienced transient right CN VI and CN VII palsies. AICA = anterior inferior cerebellar artery; BA = basilar artery; PICA = posterior inferior cerebellar artery; $\mathrm{SCA}=$ superior cerebellar artery; VA = vertebral artery. Panel C dissection prepared by Kaan Yagmurlu, MD. Reproduced with permission from the Rhoton Collection (http://rhoton.ineurodb.org), CC BY-NC-SA 4.0 (http://creativecommons.org/licenses/ by-nc-sa/4.0). Figure is available in color online only.

nial tumors but account for $18 \%$ of pediatric brain tumors and $25 \%$ of posterior fossa tumors in general, with no predilection by sex. ${ }^{8,40}$ Brainstem tumors are either diffuse or circumscribed. For diffuse brainstem tumors, particularly those confined to the pons, complete surgical removal is not feasible. Circumscribed tumors can be located dorsally, laterally, ventrally, or transitionally, and surgery is a good option for select cases.

Elhammady and $\mathrm{Teo}^{12}$ reported on their experience with resection of brainstem tumors in a cohort of 31 adult patients. They noted a mortality rate of $0 \%$ but an overall morbidity rate of $51.6 \%$, with a $38.7 \%$ rate of transient deficits and a $12.9 \%$ rate of permanent deficits. In a pediatric series $^{8}$ of 207 surgically treated tumors of the brainstem, the operative mortality in the first 2 months after surgery was $1.9 \%$ and the surgical morbidity rate was $21.2 \%$.

In general, we reserve resection of brainstem tumors for very select cases of gliomas. These include cases of juvenile pilocytic astrocytomas or other tumors that possess an exophytic component, cases in which the tumor type may be unclear and an excisional biopsy would assist with tailoring treatment, and cases in which the tumor may be expected to possess an acceptable plane with the normal brain.

\section{Conclusions}

The selection of an approach for resection of intrinsic brainstem lesions is critical to minimizing morbidity. A pessimistic view of the outcome of pathology involving the brainstem often precludes operation in this region; however, with the exception of infiltrative gliomas without an exophytic component involving the brainstem, most intrinsic brainstem lesions can be readily resected with acceptable morbidity. When selecting an approach, the surgeon should combine knowledge about the pathology and its natural history, patient life expectancy and wishes, existing deficits and the likelihood of introducing new deficits with anatomical knowledge, safe-entry zones, and the two-point method to approach and address pathologies 

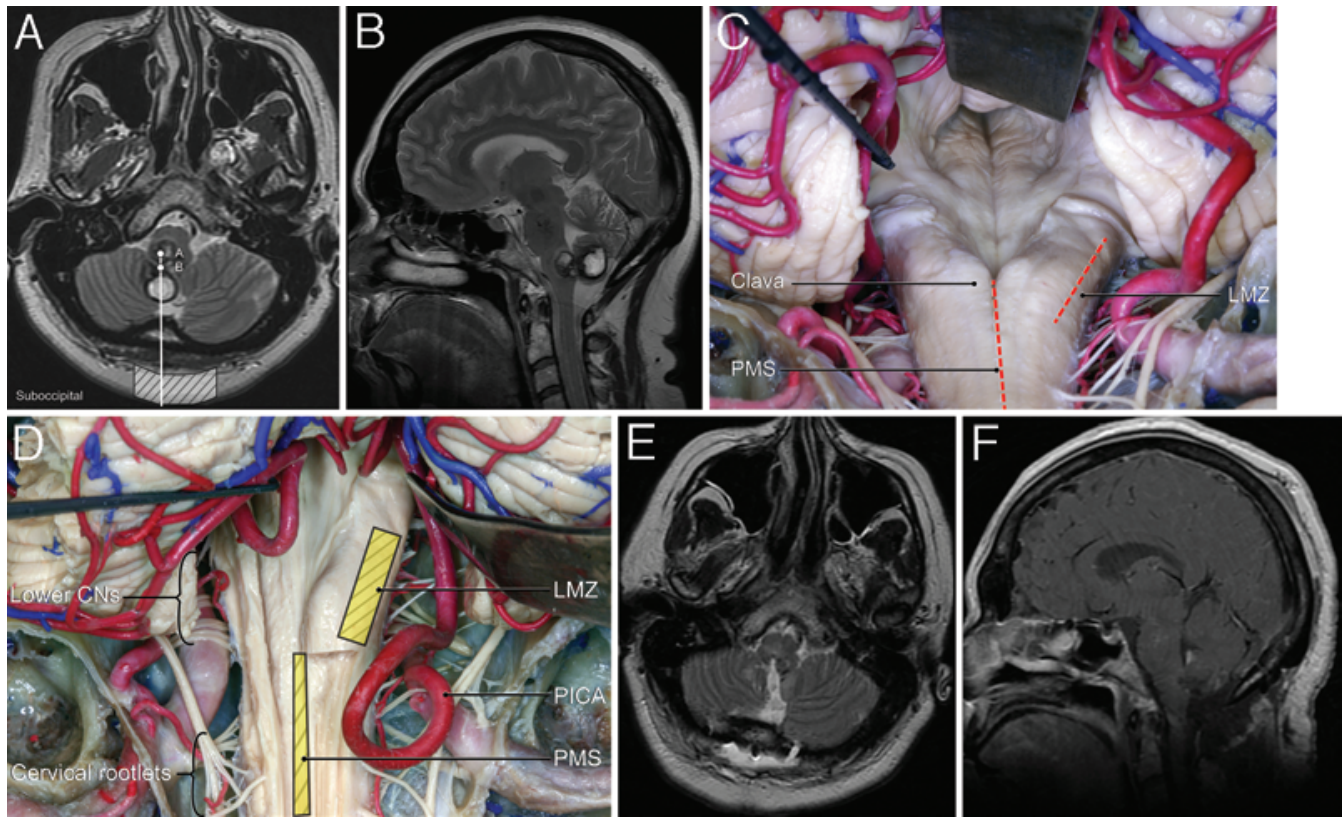

FIG. 11. Approach for a dorsal medullary lesion. A 51-year-old woman presented obtunded, and preoperative examination of cranial nerves was not possible. Axial (A) and sagittal (B) T2-weighted MRI scans demonstrate a dorsal medullary and a cerebellar cavernous malformation that abuts a pial plane at the level of the dorsal medulla. The two-point method suggests that this lesion should be approached using a posterior midline approach $(A$, white line). This lesion was approached using a suboccipital craniotomy (A, shaded hatched area). The safe-entry zone used for exposure of lesions in the posterior medulla is the posterior median sulcus (PMS) safe-entry zone (C, dashed line) and is located below the obex and laterally restricted by the clava. This sulcus can be opened akin to opening of the midline spinal cord ( $\mathbf{D}$; hatched areas show safe-entry zones). Postoperative axial T2-weighted (E) and sagittal T1-weighted (F) MR images demonstrate complete removal of the lesion. Postoperative examination revealed right CN XII and CN VII palsies as well as significant dysphagia. LMZ = lateral medullary zone. Panel C and D dissections prepared by Kaan Yagmurlu, MD. Reproduced with permission from the Rhoton Collection (http://rhoton.ineurodb.org), CC BY-NC-SA 4.0 (http://creativecommons.org/licenses/by-nc-sa/4.0). Figure is available in color online only.

in the brainstem. In this report, we have highlighted the experience of the senior author (R.F.S.) with treatment of more than 500 patients with brainstem lesions and have attempted to preserve the essence and distill the finer technical details obtained from this rich experience for surgeons and students of brainstem surgery.

\section{Acknowledgments}

We thank the staff of Neuroscience Publications at Barrow Neurological Institute. The anatomical dissections and photography were performed by Kaan Yagmurlu, MD, and are used with permission from the Rhoton Collection.

\section{References}

1. Abla AA, Lekovic GP, Turner JD, de Oliveira JG, Porter R, Spetzler RF: Advances in the treatment and outcome of brainstem cavernous malformation surgery: a single-center case series of 300 surgically treated patients. Neurosurgery 68:403-415, 2011

2. Abla AA, Spetzler RF: Brainstem cavernoma surgery: the state of the art. World Neurosurg 80:44-46, 2013

3. Bertalanffy H, Tissira N, Krayenbühl N, Bozinov O, Sarnthein J: Inter- and intrapatient variability of facial nerve response areas in the floor of the fourth ventricle. Neurosurgery 68 (1 Suppl Operative):23-31, 2011

4. Bricolo A: Surgical management of intrinsic brain stem gliomas. Oper Tech Neurosurg 3:137-154, 2000
5. Bricolo A, Turazzi S: Surgery for gliomas and other mass lesions of the brainstem. Adv Tech Stand Neurosurg 22:261341, 1995

6. Brown AP, Thompson BG, Spetzler RF: The two-point method: evaluating brain stem lesions. BNI Q 12:20-24, 1996

7. Cavalcanti DD, Preul MC, Kalani MY, Spetzler RF: Microsurgical anatomy of safe entry zones to the brainstem. J Neurosurg 124:1359-1376, 2016

8. Cavalheiro S, Yagmurlu K, da Costa MD, Nicácio JM, Rodrigues TP, Chaddad-Neto F, et al: Surgical approaches for brainstem tumors in pediatric patients. Childs Nerv Syst 31:1815-1840,2015

9. de Oliveira JG, Lekovic GP, Safavi-Abbasi S, Reis CV, Hanel RA, Porter RW, et al: Supracerebellar infratentorial approach to cavernous malformations of the brainstem: surgical variants and clinical experience with 45 patients. Neurosurgery 66:389-399, 2010

10. Deshmukh VR, Rangel-Castilla L, Spetzler RF: Lateral inferior cerebellar peduncle approach to dorsolateral medullary cavernous malformation. J Neurosurg 121:723-729, 2014

11. Dukatz T, Sarnthein J, Sitter H, Bozinov O, Benes L, Sure U, et al: Quality of life after brainstem cavernoma surgery in 71 patients. Neurosurgery 69:689-695, 2011

12. Elhammady MS, Teo C: Surgical management of adult intrinsic brainstem tumors. Neurosurgery 60 (Suppl 1):131138, 2013

13. Fritschi JA, Reulen HJ, Spetzler RF, Zabramski JM: Cavernous malformations of the brain stem. A review of 139 cases. Acta Neurochir (Wien) 130:35-46, 1994

14. Garcia RM, Ivan ME, Lawton MT: Brainstem cavernous malformations: surgical results in 104 patients and a pro- 
posed grading system to predict neurological outcomes. Neurosurgery 76:265-278, 2015

15. Garner TB, Del Curling O Jr, Kelly DL Jr, Laster DW: The natural history of intracranial venous angiomas. J Neurosurg 75:715-722, 1991

16. Gross BA, Batjer HH, Awad IA, Bendok BR, Du R: Brainstem cavernous malformations: 1390 surgical cases from the literature. World Neurosurg 80:89-93, 2013

17. Ishihara H, Bjeljac M, Straumann D, Kaku Y, Roth P, Yonekawa Y: The role of intraoperative monitoring of oculomotor and trochlear nuclei-safe entry zone to tegmental lesions. Minim Invasive Neurosurg 49:168-172, 2006

18. Kalani MYS, Lei T, Martirosyan NL, Oppenlander ME, Spetzler RF, Nakaji P: Endoscope-assisted supracerebellar transtentorial approach to the posterior medial temporal lobe for resection of cavernous malformation. Neurosurg Focus 40 (Suppl 1):V18, 2016

19. Kalani MY, Martirosyan NL, Nakaji P, Spetzler RF: The supracerebellar infratentorial approach to the dorsal midbrain. Neurosurg Focus 40 (Suppl 1):V17, 2016

20. Kalani MY, Yagmurlu K, Martirosyan NL, Spetzler RF: The retrosigmoid petrosal fissure transpeduncular approach to central pontine lesions. World Neurosurg 87:235-241, 2016

21. Kim DS, Park YG, Choi JU, Chung SS, Lee KC: An analysis of the natural history of cavernous malformations. Surg Neurol 48:9-18, 1997

22. Lemole GM Jr, Henn JS, Zabramski JM, Spetzler RF: Modifications to the orbitozygomatic approach. Technical note. J Neurosurg 99:924-930, 2003

23. Li D, Yang Y, Hao SY, Wang L, Tang J, Xiao XR, et al: Hemorrhage risk, surgical management, and functional outcome of brainstem cavernous malformations. J Neurosurg 119:996-1008, 2013

24. Macdonald DB, Skinner S, Shils J, Yingling C: Intraoperative motor evoked potential monitoring - a position statement by the American Society of Neurophysiological Monitoring. Clin Neurophysiol 124:2291-2316, 2013

25. Mai JC, Ramanathan D, Kim LJ, Sekhar LN: Surgical resection of cavernous malformations of the brainstem: evolution of a minimally invasive technique. World Neurosurg 79:691-703, 2013

26. Mathiesen T, Edner G, Kihlström L: Deep and brainstem cavernomas: a consecutive 8-year series. J Neurosurg 99:3137,2003

27. McLaughlin MR, Kondziolka D, Flickinger JC, Lunsford S, Lunsford LD: The prospective natural history of cerebral venous malformations. Neurosurgery 43:195-201, 1998

28. Monaco EA, Khan AA, Niranjan A, Kano H, Grandhi R,
Kondziolka D, et al: Stereotactic radiosurgery for the treatment of symptomatic brainstem cavernous malformations.

Neurosurg Focus 29(3):E11, 2010

29. Moriarity JL, Wetzel M, Clatterbuck RE, Javedan S, Sheppard JM, Hoenig-Rigamonti K, et al: The natural history of cavernous malformations: a prospective study of 68 patients. Neurosurgery 44:1166-1173, 1999

30. Oppenlander ME, Chowdhry SA, Merkl B, Hattendorf GM, Nakaji P, Spetzler RF: Robotic autopositioning of the operating microscope. Neurosurgery 10 (Suppl 2):214-219, 2014

31. Otten P, Pizzolato GP, Rilliet B, Berney J: [131 cases of cavernous angioma (cavernomas) of the CNS, discovered by retrospective analysis of 24,535 autopsies.] Neurochirurgie 35:82-83, 128-131, 1989 (Fr)

32. Pandey P, Westbroek EM, Gooderham PA, Steinberg GK: Cavernous malformation of brainstem, thalamus, and basal ganglia: a series of 176 patients. Neurosurgery 72:573-589, 2013

33. Porter RW, Detwiler PW, Spetzler RF, Lawton MT, Baskin JJ, Derksen PT, et al: Cavernous malformations of the brainstem: experience with 100 patients. J Neurosurg 90:50-58, 1999

34. Robinson JR, Awad IA, Little JR: Natural history of the cavernous angioma. J Neurosurg 75:709-714, 1991

35. Robinson JR Jr, Awad IA, Magdinec M, Paranandi L: Factors predisposing to clinical disability in patients with cavernous malformations of the brain. Neurosurgery 32:730-736, 1993

36. Spetzler RF, Sanai N: The quiet revolution: retractorless surgery for complex vascular and skull base lesions. J Neurosurg 116:291-300, 2012

37. Thirumala PD, Carnovale G, Habeych ME, Crammond DJ, Balzer JR: Diagnostic accuracy of brainstem auditory evoked potentials during microvascular decompression. Neurology 83:1747-1752, 2014

38. Washington CW, McCoy KE, Zipfel GJ: Update on the natural history of cavernous malformations and factors predicting aggressive clinical presentation. Neurosurg Focus 29(3):E7, 2010

39. Yagmurlu K, Rhoton AL Jr, Tanriover N, Bennett JA: Threedimensional microsurgical anatomy and the safe entry zones of the brainstem. Neurosurgery 10 (Suppl 4):602-620, 2014

40. Yaşargil MG: Microneurosurgery. Stuttgart: Thieme, 1996, $\mathrm{Vol} 4 \mathrm{~B}$

\section{Disclosures}

The authors report no conflict of interest. 